\title{
TỶ LÊ NHIỄM KHUẨN VẾT MỔ NÔNG VỚI PHƯƠNG PHÁP THAY GĂNG TRƯớC KHI ĐÓNG BUNG TRONG PHẪU THUÂT MỔ LẤY THAI
}

\author{
Hoàng Thị Diễm Tuyết*, Nguyễn Bảo Trị*, Nguyễn Thị Kim Hà*, \\ Phạm Thị Ngọc Tuyền*, Huỳnh Thị Ngọc Bích*, Nguyễn Thị Thu Thủy*, \\ Phan Thanh Sơn*, Phan Thanh Tuyền*, Nguyễn Thị Kiều Oanh*
}

\section{TÓM TẮT.}

Đặt vấn đề: Hiện nay đã có nhiều nghiên cứu chỉ những biện pháp phòng ngữa nhiếm khuẩn vết mổ hiệu quả. Gần đây có một số nghiên cứu chỉ ra rằng viểc thay găng trước khi đóng bụng trong mổ lấy thai có thể làm giảm nhiếm trùng vết mô. Mục tiêu: Đánh giá hiệu quả giảm biến chứng vết mổ nông của phương pháp thay găng so với không thay găng trước khi đóng phúc mạc thành bụng trong phâuu thuật mổ lấy thai. Phương pháp: Thử nghiệm lâm sàng ngẫu nhiên có nhóm chứng. Tại Bệnh viện Hùng Vương, nghiên cứu thực hiện từ tháng 12/2020 đến tháng $3 / 2021$ trên 629 sản phụ trong đó 319 nhóm chứng và 310 nhóm can thiêp. Tất cá nhóm phẫu thuât cho những sản phụ thuộc nhóm can thiệp sẽ được thay găng trước khi đóng phục mạc thành bụng. Chúng tối tiến hành đánh giá lần 1 vào ngày 3 hoặc ngày 4 hậu phẫu và lần 2 vào ngày $30 \pm 2$ hậu phấu. Biến chứng vết mổ nông gồm chảy dich vết mổ, nhiễm trùng vết mổ. Kết quả: tỷ lể biển chứng vết mổ nông của nhóm không thay găng và của nhóm thay găng lần lướt là $7,8 \%$ và $2,6 \%$. Sư khác biêt của hai nhóm có ý nghĩa thống kê $p=0,005$ ( OR: 0,29; KTC 95\%: 0,13 $-0,68)$. Kết luân: Thay găng làm giảm tỷ lệ biến chứng vết mổ nổng trong phẫu thuật mổ lấy thai. Có thể áp dụng vào quy trình mổ lấy thai để giảm tỷ lệ nhiễm trùng vết mổ.

Tư khóa: biến chứng vết mổ nông, thay gang.

\section{SUMMARY \\ THE RATE OF SURGICAL SITE INFECTION WITH CHANGING GLOVE DURING CEASREAN SECTION}

Introduction: Many clinical trials explored the implication of various intervention strategies to reduce SSI rate following cesarean section. Several studies have showed that glove changing during a procedure decrease wound related complications. Purpose: To compare the rates of wound related complications among women undergoing a cesarean section when the surgical team used intra-operative glove changing versus usual care. Methods: In Hung Vuong Hospital, From Dec 2020 to Mar 2021, 319 women were randomized to usual care and 310 women were randomized to intra-operative glove changing.All women undergoing a cesarean section were

*Bệnh viện Hùng Vương

Chịu trách nhiệm chính: Nguyễn Bảo Trị

Email: baotribvhv09@yahoo.com.vn

Ngày nhận bài: 11.8 .2021

Ngày phản biện khoa học: 4.10.2021

Ngày duyệt bài: 15.10.2021 randomized to usual care or intra-operative glovechanging prior to abdominal closure. The primary outcome was any wound related complication, including seroma, wound infection. Results: Intraoperative glove changing led to a significant decrease in composite wound complications from $7.8 \%$ in the control group to $2.6 \%$ in the intervention group $(p=0.005)$. Conclusion: Changing gloves during cesarean prior to abdominal wall closure may decrease the incidence of wound complications following cesarean section.

Key word: wound related complications, Intraoperative glove changing

\section{I. ĐĂTT VẤN ĐỀ}

Mổ lấy thai giúp giảm tỷ lệ tỷ lệ tử vong và bệnh tật ở mẹ và thai nhi nhưng gia tăng tỷ lệ mổ lấy thai cũ̃ng tăng nguy cơ xảy ra tai biến, biến chứng phẫu thuật. Nhiễm trùng vết mổ là một trong những biến chứng phổ biến trong phẫu thuật mổ lấy thai, tỷ lệ từ 3-5\%.

Hiện nay đã có những biện pháp phòng ngừa nhiễm khuẩn vết mổ hiệu quả được áp dụng. Gần đây có một số nghiên cữu chỉ ra rằng việc thay găng trong quá trình phẫu thuật có thể làm giảm nhiểm trùng vết mổ.

Một nghiên cứu năm 2016 của Jonathan D. Scracfford trên 553 sản phụ, báo cáo biến chứng vết mổ ở nhóm có thay găng và không thay găng $(6,4 \%-13,3 \%, P=0,008)$, điều đó nghĩa là việc thay găng trong lúc đóng bụng làm giảm tỷ lệ biến chứng vết mổ sau mổ lấy thai.

Do đó chúng tôi thực hiện nghiên cứu "Tỷ lệ nhiễm khuẩn vết mổ nồng với phương pháp thay găng trước khi đóng cân trong phẫu thuật mổ lấy thai". Mục tiêu nghiên cứu:

Đánh giá hiệu quả giảm biến chứng vêt mô nông của phương pháp thay găng so với không thay găng trước khi đóng phúc mac thành bụng trong phẫu thuật mổ lấy thai tại bệnh viện Hùng vương 2020.

Đánh giá các yêu tố liên quan đên biên chứng vêt mổ nông trong phẫu thuật mố lây thai.

II. Đốl TƯỢNG VÀ PHƯƠNG PHÁP NGHIÊN CỨU

Thiết kế nghiên cứu. Thử nghiệm lâm sàng ngẫu nhiên có nhóm chứng

Địa điểm - thời gian lấy mẫu. Tại Bệnh Viện Hùng Vương, từ tháng 03/2020 đến tháng 


\section{3/2021}

Tiêu chuẩn chọn mẫu. Sản phụ từ 18 tuổi trở lên sinh sống tại TPHCM và các tỉnh lân cận, được mổ lấy thai tại bênh viện Hùng Vương.

Tiêu chí loại ra. Sốt trong chuyển dạ, bệnh lý nhiễm trùng toàn thân và tại vị trí vết mổ, bệnh lý nội khoa đi kèm đang tiển triển

Tiêu chuẩn ngừng lấy mẫu. Trong quá trình phẫu thuật mổ lây thai: cần phải hồi sức cấp cứu tuần hoàn, tổn thương các tạng vùng chậu, phẫu thuật lần 2 do như tụ máu vết may cơ tử cung, tụ máu vùng chậu, xuất huyết nội do chảy máu vị trí may cơ tử cung, tổn thương mạch máu, Ế kíp mổ mang hai găng, thủng găng phải thay găng.

Cỡ mẫu. 629 sản phụ phân bổ ngẫu nhiên nhóm chứng: 319 và nhóm can thiệp: 310

Biến số kết cục: biến chứng vết mổ nông, gồm có nhiễm trùng vết mổ và chảy dịch vết mố. Nhiễm khuẩn vết mổ nông (theo tiêu chuẩn chẩn đoán nhiễm khuẩn vết mổ của $C D C$ ): nhiễm khuẩn xảy ra trong vòng 30 ngày sau phẫu thuật và chỉ xuất hiện ở vùng da hay vùng dưới da tại đường mổ và̀ có ít nhất một trong các triệu chứng: Chảy mủ từ vết mổ nông, phân lập được vi khuẩn từ vết mổ, các dấu hiệu đau sưng nóng đỏ và cần mở bung vết mổ

\section{Phương pháp tiến hành}

Bước 1: phân bổ ngẫu nhiên 629 sản phụ vào 2 nhóm

Bước 2: thực hiện can thiệp lúc phẫu thuật mổ lấy thai

Nhóm can thiệp thay găng trước khi đóng phúc mạc thành bụng hoặc trước khi đóng cân nếu không đóng phúc mạc

Nhóm chứng không thay găng

Bước 3: Thu thập số liệu lần 1 vào ngày 3 hoặc ngày 4 hậu phẫu, lần 2 vào ngày $30 \pm 2$ hậu phấu.

\section{KẾT QUẢ NGHIÊN CứU}

Nghiên cứu tiến hành thu thập số liệu tại Bệnh viện Hùng Vương từ tháng 12/2020 đển 03/2021, thu nhận 629 sản phụ, gồm 319 nhóm chứng và 310 can thiệp.

Đặc điểm tiền sản và đặc điểm thai kỳ

\begin{tabular}{|c|c|c|}
\hline Đặc điểm & $\begin{array}{c}\text { Nhóm } \\
\text { chứng } \\
(\mathrm{N}=319)\end{array}$ & $\begin{array}{c}\text { Nhóm can } \\
\text { thiệp } \\
(\mathrm{N}=310)\end{array}$ \\
\hline $\begin{array}{c}\text { Tuối mẹ (TB } \pm Đ L C) \\
\text { (GTNN - GTLN) }\end{array}$ & $\begin{array}{l}30,7 \pm 5,0 \\
(17-43)\end{array}$ & $\begin{array}{l}30,8 \pm 5,0 \\
(16-49)\end{array}$ \\
\hline \multicolumn{3}{|c|}{ Số con hiện tại } \\
\hline Con so & $139(43,6)$ & $121(39,0)$ \\
\hline Con rạ & $180(56,4)$ & $189(61,0)$ \\
\hline \multicolumn{3}{|c|}{ Mố lấy thai } \\
\hline Không & $172(53,9)$ & $149(48,0)$ \\
\hline
\end{tabular}

\begin{tabular}{|c|c|c|}
\hline Có & $147(46,01)$ & $161(52,0)$ \\
\hline \multicolumn{3}{|c|}{ Tuối thai (tuânn) } \\
\hline Non tháng & $13(4,1)$ & $25(8,1)$ \\
\hline Đủ tháng & $306(95,9)$ & $285(91,9)$ \\
\hline Quá ngày & 0 & 0 \\
\hline \multicolumn{3}{|c|}{ Đái tháo đường } \\
\hline Có & $63(19,7)$ & $63(20,3)$ \\
\hline Không & $256(80,3)$ & $247(79,7)$ \\
\hline \multicolumn{3}{|c|}{ Oi võ } \\
\hline Không & $252(79,0)$ & $253(81,6)$ \\
\hline Có & $67(21,0)$ & $57(18,4)$ \\
\hline \multicolumn{3}{|c|}{ Vào chuyến dạ } \\
\hline Không & $20(6,3)$ & $27(8,7)$ \\
\hline Có & $299(93,7)$ & $283(91,3)$ \\
\hline \multicolumn{3}{|c|}{ Tính chất mố lấy thai } \\
\hline Chủ động & $255(79,9)$ & $273(88,1)$ \\
\hline Cấp cứu & $64(20,1)$ & $37(11,9)$ \\
\hline $\begin{array}{l}\text { Thời gian cuộc mố } \\
\text { (phút) }\end{array}$ & $35(30-40)$ & $35(30-45)$ \\
\hline \multicolumn{3}{|c|}{ Lượng máu mất (ml) } \\
\hline$<500 \mathrm{ml}$ & $301(94,4)$ & $294(94,8)$ \\
\hline$\geq 500 \mathrm{ml}$ & $18(5,6)$ & $16(5,2)$ \\
\hline
\end{tabular}

Mối liên quan giữa biến chứng vết mố nông và thay găng

\begin{tabular}{|c|c|c|c|c|}
\hline \multirow{2}{*}{$\begin{array}{l}\text { Đăc } \\
\text { điểm }\end{array}$} & \multicolumn{2}{|c|}{$\begin{array}{l}\text { Biến chứng vết } \\
\text { mổ nông }\end{array}$} & \multirow[t]{2}{*}{$\mathbf{P}$} & \multirow[t]{2}{*}{ OR } \\
\hline & $\begin{array}{c}\text { Có } \\
(\mathrm{N}=33)\end{array}$ & $\begin{array}{c}\text { Không } \\
(N=596)\end{array}$ & & \\
\hline \multicolumn{5}{|c|}{ Thay găng } \\
\hline Có & $8(2,6)$ & $302(97,4)$ & & 0,29 \\
\hline Không & $\begin{array}{c}25 \\
(7,8) \\
\end{array}$ & $\begin{array}{c}294 \\
(92,2)\end{array}$ & 0,005 & $\begin{array}{l}(0,13- \\
0,68)\end{array}$ \\
\hline
\end{tabular}

Mối liên quan giữa biến chứng vết mố nông và các yếu tố

\begin{tabular}{|c|c|c|}
\hline Đặc điếm & OR (KTC 95\%) & p \\
\hline Öi võ & $3,27(1,56-6,85)$ & 0,002 \\
\hline \multicolumn{3}{|c|}{ Thời gian từ nhâp viên đến mố (giờ) } \\
\hline $12-24$ giờ & $5,54(1,11-27,7)$ & 0,037 \\
\hline ASA & $10,25(3,06-34,28)$ & 0,033 \\
\hline $\begin{array}{l}\text { Phâu thuâtt sử dụng } \\
\text { thêm: cắt tử cung }\end{array}$ & $\begin{array}{c}22,72(2,20- \\
235,26)\end{array}$ & 0,009 \\
\hline
\end{tabular}

\section{BÀN LUÂN}

Các đặc điểm cơ bản về dân số, tiền sản, đặc điểm thai kỳ, yếu tố liên quan phẫu thuật như chỉ định, tính chất phẫu thuật, kinh nghiệm phẫu thuật viên... không khác biệt giữa hai nhóm nghiên cứu.

Tuổi trung bình của 2 nhóm là 30 tuổi, độ tuổi sinh sản trung bình của phụ nữ. $55,2 \%$ $53,9 \%$ sản phụ đến từ những tỉnh thành khác, phù hợp tình trạng nhập cư của TPHCM. Trình độ học vấn THPT chiếm 52,4\% - 53,6\%, đại học, sau đại học chiếm $40,6 \%$ - 42\% và điêu kiện kinh tể cũng tương đồng giữa hai nhóm. 
Trong các phẫu thuật mổ lấy thai trong nghiên cứu được phân loại ASA độ I có 22 trường hợp và ASA độ II 607, tương đồng giữa 2 nhóm. Một nghiên cứu Vũ Hương Huyên thực hiện trên 609 sản phụ, kết quả cho thấy so với những sản phụ có điểm số ASA dưới 3, những sản phụ có điểm số ASA từ 3 điểm trở lên có nguy cơ rối loạn lành vết mổ cao hơn 10,57 lần [6].

Tuổi thai trung bình của chúng tôi là 38,3 38,5 tuần, tương đồng những nghiên cứu có liên quan đến mổ lấy thai khác tại Việt Nam như theo Vũ Duy Minh, Tuổi thai trung bình là 38,4 tuần được mổ lấy thai tại BV Từ Dũ

Tỷ lệ con so trong nghiên cứu chúng tôi chiếm $39 \%-43,6 \%$. Tỷ lệ con so của nghiên cứu Nguyễn Quỳnh Chi năm 2015 thực hiện tại Bệnh viện Từ Dũ là 46\% [3]. Sự chênh lệch cửa 2 tỷ lệ này có thể do trong nghiên cứu Nguyễn Quỳnh Chi chỉ xét đến tình trạng lành vết mổ, trong khi nghiên cứu chúng tôi đánh giá biến chứng vết mổ nông bao gồm nhiễm trùng vết mổ, chảy dich vết mổ và tụ máu vết mổ.

Năm 2009 tại Bênh Viện Hùng Vương, 27,5\% sản phụ được mổ lấy thai là có vết mổ lấy thai cũ , tỷ lệ này tăng lên $36,6 \%$ năm 2017 và lên 46,1\% - 52\% trong năm 2021 của nghiên cứu chúng tôi. Tỷ lệ chúng tôi cao hơn tỷ lệ có vết mổ cũ của Nguyễn Quỳnh Chi là $32,6 \%$ năm 2015 tại Bệnh viện Từ Dũ [3].

$93,1 \%-95,8 \%$ sản phụ có khám thai từ $3-$ 8 lần, đều đó chứng tỏ sự nhận thức về vai trò khám thai của sản phụ tốt, qua đó đánh giá nguy cơ, phát hiện sớm bệnh lý của thai và mẹ.

Theo thống kề của khoa Sản bệnh Bệnh viện Hùng Vương, tỷ lệ đái tháo đường thai lý tại bệnh viện tăng dần theo thời gian, và đạt $18 \%$ và̀o năm 2017 phù hợp tỷ lệ đái tháo đường liên quan đến thai kỳ của chúng tôi là $19,7 \%$ 20,3\%. 100\% các trường hợp thu nhận đái tháo đường của chúng tôi đều được điều trị bằng cách tiết chế trong chế độ ăn, không có trường hợp nào cần sử dụng insulin.

Tỷ lệ ối vỡ 18,4\% - 21\%, trong đó ối võ trên 24 giờ là $2 \%-2,5 \%$. Tỷ lệ chúng tôi không quá khác biệt với tỷ lệ ối vỡ trong nhóm mổ lây thai của Robson 1 của Đoàn Vũ Đại Nam năm 2015 là $22 \%$. Tỷ lệ sản phụ có tình trạng ối võ̃ sớm Bệnh Viện Từ Dũ vào năm 2009 chiếm 28,1\%.

Thời gian từ lúc nhập viện đến khi mổ lấy thai dưới 12 giờ chiếm 77,7\% - 78,6\%, nghiên cứu chúng tôi phù hợp mô hình bệnh tật của Bệnh viện Hùng Vương, đa phần các ca mổ lãy thai từ khoa sanh, và tỷ lệ vào chuyển dạ của nhóm nghiên cứu là gần $90 \%$.
Chúng tôi ghi nhận số lần thăm khám âm đạo $\leq 4$ lần chiếm 95,5\%-96,9\%. Theo Vũ Duy Minh, đa số sản phụ nhập viện được thực hiện mổ lấy thai trong thời gian nhỏ hơn $\dot{1}$ ngày chiếm 67,2\% tại Bệnh viện Từ Dũ.

Trong nghiên cứu chúng tôi tỷ lệ đơn thai là $97,7 \%-98,4 \%$ và tỷ lệ ngôi đâu là $89 \%-90,9 \%$. Tỷ lệ này tương đồng với nghiên cứu Vũ Duy Minh, ngôi đầu chiếm tỉ lệ cao nhất $86,7 \%$, tiếp theo là ngôi mông $10,4 \%$ còn ngôi ngang và ngôi thai khác chiếm tỉ lệ không đáng kể.

Tai Bệnh Viện Từ Dũ, theo Vũ Duy Minh, thời gian điều trị trung bình cho một trường hợp mô lấy thai là 6,7 ngày, trong khi số ngày trung bình nằm viện của chúng tôi là 4,55 - 4,67 ngày.

Trong các ca mổ chúng tôi ghi nhận 95,2\% $96,2 \%$ là thực hiện mổ lấy thai đơn thuần và những trường hợp còn lại thực hiện thêm các thủ thuật khác như thắt động mạch tử cung, bóc nang, bóc u xơ tử cung trong khi tại Bệnh Viện Từ Dũ tỷ lệ thêm phẫu thuât khác là 3,7\% [3].

Biến chứng vết mổ nông. Nghiên cứu chúng tôi cho thấy tỷ lệ biến chứng vết mổ nông của nhóm không thay găng và của nhóm thay găng lần lượt là $7,8 \%$ và $2,6 \%$. Sự khác biệt của hai nhóm có ý nghĩa thống kê $\mathrm{p}=0,005$ (OR: 0,29 ; KTC $95 \%: 0,13-0,68$ ). Điều này chứng minh việc thay găng giảm tỷ lệ biến chứng vết mổ nông trong điều kiện chăm sóc và điều trị tại Bệnh Viện Hùng Vương.

Các yếu tố liên quan đến biến chứng vết mổ: Thai phụ được thay găng trước khi đóng bụng trong phẫu thuật mổ lấy thai có số chênh biến chứng vết mổ nông bằng 0,29 lần (KTC 95\%: $0,13-0,68$ ) so với bệnh nhân không được thay găng trước khi đóng bụng trong phẫu thuật mổ lấy thai với $p=0,005$.

Bên cạnh đó, thai phụ có tổng số lần khám thai $>8$ có số chênh biển chứng vết mổ nông gấp 3,43 lần (KTC 95\%: 1,05 - 11,34) so với thai phụ có tổng số lần khám thai từ 3 đến 8 lần, sự khác biệt này có ý nghĩa thống kê vì $p=0,042$.

Mặt khác, thai phụ có ối võ̃ có số chênh biến chứng vết mổ nông gấp 3,27 lần (KTC 95\%: $11,56-6,85)$ so với những thai phụ không vỡ ối, mối liên quan này có ý nghĩa thống kê $p=0,002$.

Thời gian từ lúc nhập viện đến lúc mổ từ 12 24 giờ làm tăng biến chứng vết mổ nông gấp 5,54 lần (KTC 95\%: 1,11 - 27,7) so với thời gian từ lúc nhập viện đến lúc mổ < 12 giờ, mối liên quan này có ý nghĩa thống kê với $p=0,037$.

Ngoài ra, thai phụ có ASA cao hơn 1 đơn vị thì số chênh biến chứng vết mổ nông gấp 10,25 lần (KTC 95\%: 13,06 - 34,28), mối liên quan này 
có ý nghĩa thống kê $\mathrm{p}<0,001$.

Và thai phụ trong cuộc mổ lấy thai phải thêm phẫu thuật cắt tử cung có số chênh biến chứng vết mổ nông gấp 22,72 lần (KTC 95\%: 2,20 $235,26)$ những thai phụ không thêm phẫu thuật, thủ thuật, mối liên quan này có ý nghĩa thống kê $\mathrm{p}=0,009$.

Tuy nhiên, phân tích mô hình hồi quy đa biến, mối liên quan giữa biến chứng vết mổ nông và thời gian cuộc mổ, chuyển dạ kéo dài, tuổi thai.

\section{KẾT LUÂNN}

Nghiên cứu thực hiện 629 sản phụ và cho thây kết quả: tỷ lệ biến chứng vết mổ nông của nhóm không thay găng và của nhóm thay găng lần lượt là $7,8 \%$ và $2,6 \%$. Sự khác biệt của hai nhóm có ý nghĩa thống kê $\mathrm{p}=0,005$ (OR: 0,29; 95\%KTC: $0,13-0,68)$.

Các yếu tố liên quan đến biến chứng vết mổ nông: ối võ có số chênh biến chứng vết mổ nông gấp 3,27 lần (KTC 95\%: 11,56-6,85) với $p=$ 0,002 , thời gian từ lúc nhập viện đến lúc mổ từ 12 - 24 giờ làm tăng biến chứng vết mổ nông gấp 5,54 lần (KTC 95\%: 1,11 - 27,7) với $\mathrm{p}=$ 0,037 , thai phụ trong cuộc mổ lấy thai phải thêm phẫu thuật cắt tử cung có số chênh biến chứng vết mổ nông gấp 22,72 lần (KTC 95\%: 2,20 $235,26)$ với $p=0,009$.C

\section{KIẾN NGH!}

Cập nhật thay găng trước khi đóng bụng vào trong Quy trình phẫu thuật mổ lấy thai. Tuy nhiên, thay găng chì là 1 biện pháp giảm nhiễm khuẩn vết mổ, bên cạnh biện pháp khác như: giảm thời gian mổ lấy thai, giảm lượng máu mất. Cần tuân thủ các quy trình chăm sóc bệnh nhân đảm bảo an toàn phẩu thuật cho các trường hợp phẫu thuật, đặc biệt lưu ý ở đối tượng vỡ ối, ASA cao, mổ lấy thai có phẫu thuật cắt tử cung kèm theo.Cần có thêm nghiên cứu đánh giá hiệu quả thay găng trước khi đóng bụng trong phẫu thuật phụ khoa, nghiên cứu đánh giá hiệu quả kinh tế của thay găng khi giảm tỷ lệ nhiếm khuẩn vết mổ, nghiên cứu đề cập bằng chứng vi sinh về nguồn vây nhiễm từ bàn tay phẫu thuật viên.

\section{TÀI LIỆU THAM KHẢO}

1. Nguyễn Quỳnh Chi (2015), "Khảo Sát Các Yếu Tố Nguy Cớ Liên Quan Đến Tình Trạng Vết Mồ Thành Bụng Trên Sản Phụ Mổ Lấy Thai Tại Bệnh Viên Từ 'ंũ".

2. Vũ Hương Huyền (2019), "Khảo Sát Tình Trang Lành Vết Mổ Thành Bung Trên Sản Phu Mổ Lẫy Thai Theo Thang Diểm Asepsis Tại Bệnh Viện Hùng Vương"

3. Md1 Jonathan D. Scrafford, Buvana Reddy, Md2, Colleen Rivard, Md1, And Rachel I. Vogel, Ph.D1 (2018), "Effect Of Intra-Operative Glove-Changing During Cesarean Section On PostOperative Complications: A Randomized Controlled Trial". Arch Gynecol Obstet, 296 (6), 1449-1454.

4. M. A. Olsen, Denise M. Butler Am Fau Willers, Preetishma Willers Dm Fau - Devkota, Gilad A. Devkota P Fau - Gross, Victoria J. Gross Ga Fau - Fraser ,V. J. Fraser Risk Factors For Surgical Site Infection After Low Transverse Cesarean Section". (0899-823x (Print)).

\title{
ĐĂC ĐIỂM LÂM SÀNG VÀ MỨC Độ NĂNG CỦA TỔN THƯƠNG PHỔI TRÊN X QUANG NGỰC Ở BÊ̂NH NHẦN NHẬP VIỆN DO COVID-19
}

\author{
Hoàng Văn Sỹ ${ }^{1}$, Nguyễn Minh Kha ${ }^{1}$, Nguyễn Thanh Phong ${ }^{2}$, \\ Huỳnh Nghĩa ${ }^{1}$, Lê Phước Truyền ${ }^{1}$, Triệu Khánh Vinh ${ }^{1}$, Đào Thị Thu Hiền ${ }^{1}$, \\ Lê Thế Đức Tài ${ }^{1}$, Trần Thanh Tòng ${ }^{1}$, Phan Văn Hiếu ${ }^{1}$, \\ Bùi Nguyễn Thùy Trang', Lê Minh Quân ${ }^{1}$, Trần Minh Đương', \\ Nguyễn Đình Thắng ${ }^{1}$, Nguyễn Nhật Tài ${ }^{1}$, Vương Thị Ngọc Lan ${ }^{1}$ \\ học đơn giản giúp chẩn đoán độ nặng và tiên lượng \\ phù hợp trong quản lý bệnh COVID-19. Dữ liệu vể \\ đánh giá độ nặng tổn thương phổi trên $X$ quang ở \\ bệnh nhân COVID-19 tại Việt Nam còn hạn chế. Mục \\ tiều: Nghiên cứu này được tiến hành để mô tả đặc \\ điểm lâm sàng, mức độ nặng tổn thương phổi trên $X$ \\ quang ngực ở bệnh nhẩn COVID-19 và đánh giá mối \\ liên quan giữa những yếu tố lâm sàng với độ nặng của \\ tổn thương phổi trên $X$ quang ngực. Đối tượng và \\ phương pháp nghiên cứu: Nghiền cứu hồi cứu trên \\ bệnh nhân nhiễm COVID-19 nhập viện trong khoảng \\ thời gian từ ngày 30/08/2021 đến ngày 30/09/2021. \\ Đánh giá mức độ nặng của tổn thương phổi trên $X$
}

\section{TÓM TẮT}

Mở đâu: COVID-19 đã và đang trở thành gánh nặng y tế toàn câu. $X$ quang ngực là công cụ hình ảnh

\footnotetext{
${ }^{1}$ Dại học Y Dượ TP. Hồ Chí Minh

²Bệnh viện Bệnh Nhiệt đới TP. Hồ Chí Minh

Chịu trách nhiệm chính: Hoàng Văn Sỹ

Email: hoangvansy@ump.edu.vn

Ngày nhận bài: 12.8.2021

Ngày phản biện khoa học: 5.10.2021

Ngày duyệt bài: 15.10 .2021
} 